\title{
GABA Benzodiazepine Receptors and GABA-Ergic Neurotransmission Changes in Alcohol and Nicotine Dependency
}

\author{
Behzad Saberi and Behrouz Saberi Tehrani* \\ ${ }^{1} \mathrm{MD}, \mathrm{PhD}$ \\ ${ }^{2}$ Specialist in Preventive and Community Medicine, Iran
}

*Corresponding author: Behrouz Saberi Tehrani, Specialist in Preventive and Community Medicine, Medical Research, Iran.

Received Date: February 22, 2019

Published Date: March 06, 2019

\section{Mini Review}

GABA-A receptors have an important role in modulation of the effects of ethanol in the brain. GABA receptors as ion channels which are basically ligand gated ones, modulate the inhibitory synaptic transmission in the central nervous system. Alcohol addiction phases such as withdrawal, dependency and tolerance are associated with the GABA-ergic neurotransmission changes in the brain $[1,2]$. The neuroimaging studies with PET and SPECT have demonstrated that there are lower GABA-A benzodiazepine receptors availability in alcohol dependent subjects. In tobacco smoking status, higher availabilities of GABA-A benzodiazepine receptors have been demonstrated $[3,4]$. These findings suggest that tobacco smoking may suppress increasing in the availability of GABA-A benzodiazepine receptors in alcohol addiction. Moreover, such higher availability is related with alcohol withdrawal symptoms which are more pronounced in alcohol dependent nonsmokers than smokers. Such findings suggest that by suppression of the increased GABA-A benzodiazepine receptors availability during alcohol withdrawal, tobacco smoking may block symptoms of alcohol withdrawal. Overall, availability of GABA-A benzodiazepine receptors would increase in the early stages of withdrawal and then decrease during time. Such changes are mediated by tobacco smoking. The clinical implications of such findings suggest that nicotine replacement therapy can be helpful to tolerate the nicotine and alcohol withdrawal symptoms in smokers with alcohol dependency $[3,4]$.

\section{Acknowledgement}

None.

\section{Conflict of Interest}

No conflict of Interest.

\section{References}

1. Davies M (2003) The role of GABAA receptors in mediating the effects of alcohol in the central nervous system. J Psychiatry Neurosci 28(4): 263-274.

2. Vengeliene V, Bilbao A, Molander A, Spanagel R (2008) Neuropharmacology of alcohol addiction. Br J Pharmacol 154(2): 299315.

3. Staley JK, Krishnan-Sarin S, Cosgrove KP, Krantzler E, Frohlich E, et al. (2006) Human tobacco smokers in early abstinence have higher levels of beta2 nicotinic acetylcholine receptors than nonsmokers. J Neurosci 26(34): 8707-8714.

4. Staley JK, Gottschalk C, Petrakis IL, Gueorguieva R, O Malley S, et al. (2005) Cortical gamma-aminobutyric acid type A-benzodiazepine receptors in recovery Imaging Receptor Changes in Human Drug Abusers 215 from alcohol dependence: relationship to features of alcohol dependence and cigarette smoking. Arch Gen Psychiatry 62(8): 877-888. 